\title{
Introduction to the Government and Disaster Resilience Minitrack 2018
}

\author{
Mihoko Sakurai \\ University of Agder \\ Center for Integrated Emergency \\ Management \\ 4604 Kristiansand, Norway \\ mihoko.sakurai@uia.no
}

\author{
Jose J. Gonzalez \\ University of Agder \\ Center for Integrated Emergency \\ Management \\ 4898 Grimstad, Norway \\ josejg@uia.no
}

\author{
Frederick Benaben \\ IMT Mines Albi \\ Industrial Engineering Center \\ 81000 Albi, France \\ frederick.benaben $@$ mines- \\ albi.fr
}

The term resilience has become an important policy agenda for governmental organizations, especially for local governments, where policies and actions impact citizens directly. Resilience is recognized as a measure of an ecological system's persistence and the ability to absorb disturbances while maintaining the existing relationships between system entities in its original definition [1]. The role of a local government, which is in charge of delivering basic daily services to citizens, has become more critical in dealing with social uncertainty and complexity. It requires local governments to collaborate with diverse stakeholders to tackle the problems in a long-term time span. This is what makes resilience activities unique. Disaster management is of course a part of this scope but not all activities under resilience is heading to an emergency, which should maintain a shorter time mindset.

Standing from this perspective, both research and practice demand us to pay more attention to the notion of community resilience. It also includes the necessity of consideration how to deal with the consequences of disaster events; not only during the aftermath, but also by protecting against and preventing long-term consequences before events occur. This minitrack features government (national, regional and local) entities and the roles they serve in developing disaster resilience, coordinating relief operations with different organizations. Information systems and technologies to enhance disaster resilience and capability of the government are also essential to discuss.

Two papers were accepted to this minitrack. Each paper argues the importance of having a long-term perspective to make local authorities to be more resilient. They don't address disaster or emergency issues directly, however, findings from each paper provides elaborated implications which could be useful in considering preparation for an expected event in the future. These findings especially can be applied for local governments.

"A Conceptual System Dynamics Maturity Model of City Resilience," by Jaziar Radianti, Ahmed Abdeltawab A.S Aboughonim, and Jose J. Gonzalez discusses a system dynamics maturity model for city resilience. Discussions are based on a Resilience Maturity road map, which supports cities to achieve a higher mature level of resilience. The paper addresses the following two challenges: How to design a model that allows users to perceive the importance of adopting policies that are in line with the sequence in the road-map, and how to design a model that shows the consequences of policy adoption in terms of budget and the resilience improvement reflected by the resilience indicators. Authors analyze and compare two alternative structures for exploring resilience policies to be used by city stakeholders.

Another paper, "Technology-Mediated Learning for Resilience," by Tim A. Majchrzak, Peter André Busch and Kjetil Sandvik discusses a resilient community, particular they pay attention to the learning function of resilience. Based on four actual cases from communities such as refugees, kindergarten, adults, and online course, authors analyze the impact technology has on learning about resilience. The cases illustrate that technology is not necessarily extensively used to engage citizens and to reach people that otherwise would hardly be reached. The actual way towards resilience differs a lot. The paper concludes that cities and governments should be encouraged in trying out to build resilience in a bottom-up way to explore further impact of technology to community resilience. This is a practical advice to practice given by authors, which makes paper beneficial.

[1] C.S. Holling, Resilience and Stability of Ecological Systems, Annual Review of Ecology and Systematics, 4(1), 1973, pp. 1-23. 